\title{
Sobral: A definição das políticas públicas a partir da participação popular
}

\author{
Lara Elena Ramos Simielli ${ }^{1}$
}

RESUMO: Sobral, caracterizada até meados da década de 1990 por indicadores sociais alarmantes, conseguiu reverter esta situação valendo-se de uma estrutura baseada em comitês participativos e na intersetorialidade entre os atores governamentais e não-governamentais. O Programa Sobral Criança e o Projeto Trevo de Quatro Folhas, exemplos desta estrutura, demonstram a importância da participação popular na definição das políticas públicas e os impactos que estes e outros programas tiveram na melhoria dos indicadores sociais e econômicos do município, evidenciando o impacto de uma gestão conjunta entre o Estado e a sociedade.

PALAVRAS-CHAVE: Comitês, Intersetorialidade, Programa Sobral Criança, Projeto Trevo de Quatro Folhas, Participação Popular, Políticas Públicas.

ABSTRACT: Until the mid 1990's, Sobral had alarming social indicators, which were improved due to a structure based on committees and inter-sector collaboration among governmental and non-governmental actors. Sobral Children's Program and the Four-Leaf Clover Project, examples of this structure, will be described in further detail in order to demonstrate the importance of citizen participation in defining public policies and the impact that these and other programs have had in improving social and economic indicators in the municipality of Sobral.

KEYWORDS: Committees, Inter-sector collaboration, Citizen Participation, Public Policies.

\footnotetext{
1 Mestre em Administração Pública.Trabalha no Instituto Ecofuturo, no Projeto “Ler é Preciso”, onde é responsável pelo processo de instalação de bibliotecas comunitárias. Av. Brigadeiro Faria Lima 1355. Cep 01452. E-mail: lasimielli@yahoo.com.br
} 
Sobral é uma cidade localizada a aproximadamente 200 quilômetros de Fortaleza, capital do Estado do Ceará, na região Nordeste do Brasil. Situa-se na região do semi-árido brasileiro, um dos locais mais pobres do país, com indicadores de desenvolvimento econômico e social abaixo da média dos demais estados.

Conhecida como "Princesa do Norte", Sobral é uma cidade tombada pelo Patrimônio Histórico e Artístico Nacional devido a sua arquitetura e seu patrimônio histórico e cultural. Apesar da sua herança cultural e riqueza histórica, Sobral apresentou, por muitos anos, um cenário de descaso do poder público para com as políticas sociais.

Até meados da década de 1990, Sobral apresentava indicadores sociais alarmantes. Em 1991, a mortalidade infantil era de 67 para cada 1000 nascidos vivos, em comparação a uma taxa de 47 para cada 1000 nascidos vivos no Brasil; a taxa de analfabetismo chegava a 43,7\%, praticamente o dobro do Brasil (20\%); e a expectativa de vida era de 60,6 anos seis anos a menos do que a expectativa de vida no Brasil (Instituto Brasileiro de Geografia e Estatística - IBGE, 1991; Programa das Nações Unidas para o Desenvolvimento - PNUD, 2002).

Em 1997, uma aliança entre três partidos políticos (PT - Partido dos Trabalhadores, PSDB - Partido da Social Democracia Brasileira e PPS - Partido Popular Socialista), denominada “Sobral tem Jeito”, buscou modificar este cenário, articulando uma proposta para a reversão dos baixos indicadores sociais. Foi considerado prioritário o investimento em ações e políticas públicas de caráter universal, como a educação, a saúde e o saneamento básico.

Um dos programas implementados foi o Programa Sobral Criança. Este Programa buscou aumentar a intersetorialidade entre os diversos atores governamentais e nãogovernamentais, propiciando um intercâmbio tanto entre as Secretarias (de Saúde, Educação, Assistência Social, entre outras) quanto entre o governo e a sociedade civil. O Programa foi inteiramente organizado sob a forma de comitês, cada um deles especificamente ligado a uma fase do desenvolvimento das crianças e adolescentes do município. Diversas organizações populares e entidades da sociedade civil além de secretarias e órgãos governamentais faziam parte destes comitês, evidenciando a importância da participação popular no seu funcionamento.

CADERNOS GESTÃO PÚBLICA E CIDADANIA, V. 13, N.52 - JAN./JUNHO 2008 
Mais recentemente, um novo programa, intitulado Projeto Trevo de Quatro Folhas, foi implementado no município. Este programa, voltado especificamente para a redução da morbimortalidade materna e infantil, estruturou-se a partir do auxílio de um comitê, dando continuidade à tradição iniciada com o Programa Sobral Criança.

Esta estrutura baseada nos comitês e na intersetorialidade entre os atores governamentais e não-governamentais, exemplificada pelos dois programas, propiciou o desenvolvimento das políticas públicas como o resultado de uma gestão conjunta entre o Estado e a sociedade.

Atualmente, mais de dez anos após o lançamento desta aliança supra-partidária e destes programas, os impactos sobre os indicadores sociais do município são bastante relevantes. A taxa de mortalidade infantil em 2005, por exemplo, foi de 22,9 a cada 1000 nascidos vivos (Instituto de Pesquisa e Estratégia Econômica do Ceará - IPECE, 2006) - uma queda de 66\% em relação aos dados de 1991.

Neste artigo, iremos descrever com maior detalhamento as características do Programa Sobral Criança e do Projeto Trevo de Quatro Folhas, buscando demonstrar a importância da participação popular na definição das políticas públicas e os impactos que estes e outros programas tiveram na melhoria dos indicadores sociais e econômicos do município de Sobral.

\section{Características dos Programas}

De acordo com o último censo realizado pelo IBGE, em 2000, Sobral era a terceira maior cidade do Estado do Ceará, com 155.276 habitantes. Deste total de habitantes, 42\% tinham menos de 18 anos - revelador da predominância dos jovens na estrutura etária do município. Por conta disso, e também levando em consideração o fato de que a população de Sobral é predominantemente urbana ( $87 \%$ da população vive na cidade, de acordo com o PNUD, 2002), havia a necessidade de priorizar o investimento em crianças e adolescentes, principalmente aqueles em situação de maior vulnerabilidade.

O Programa Sobral Criança ${ }^{2}$ foi um projeto desenvolvido justamente para atender este público, num contexto mais amplo de reversão dos baixos indicadores sociais do município.

\footnotetext{
${ }^{2}$ Para mais informações sobre o Programa Sobral Criança, ver CARNEIRO, Carla Bronzo Ladeira. Programa Sobral Criança. In: FARAH, Marta Ferreira Santos e BARBOZA, Hélio Batista. Novas Experiências de Gestão Pública e Cidadania: Ciclo de Premiação 1999. São Paulo: Programa Gestão Pública e Cidadania, 2000.
} 
A partir da iniciativa da Prefeitura de Sobral e da coordenação da Fundação de Ação Social, vinculada à Secretaria de Saúde e Assistência Social, foram organizados três comitês para a definição e implementação das políticas públicas, focados nas questões da saúde, educação e profissionalização dos jovens.

O Comitê Nascer em Sobral, o primeiro a ser criado, concentra-se na questão da saúde da gestante e do recém-nascido, com especial foco no combate à mortalidade infantil. Entregase para a gestante, durante sua primeira consulta pré-natal, a Caderneta de Saúde da Mãe e da Criança, que contém informações importantes para as futuras mães, abordando desde a sexualidade, até o parto e a amamentação do recém-nascido. Esta caderneta permite aos médicos um rigoroso acompanhamento das gestantes e bebês, evitando problemas de saúde futuros. Além da Caderneta de Saúde da Mãe e da Criança, são discutidos projetos de prevenção de gravidez na adolescência, acompanhamento e assistência à gestante de risco e estruturação do pré-natal de risco. Participam deste comitê diversas secretarias, associações e entidades, como: Secretarias de Saúde e Assistência Social, Conselhos Municipais (de direitos, tutelares, de assistência e de saúde), Conselho Regional de Medicina, Câmara Municipal, Poder Judiciário, Santa Casa, igrejas, a Diocese, o Hospital, a Associação dos Agentes de Saúde e a Federação Sobralense de Associações Comunitárias, entre outras.

O Comitê Crescer e Desenvolver em Sobral atua na questão da educação, tanto formal quanto informal, da cultura e da socialização das crianças e adolescentes. É liderado pela Secretaria da Educação e, assim como o Comitê Nascer em Sobral, agrega diversas entidades, governamentais e não-governamentais: Secretarias Municipais de Saúde e Assistência Social, de Desenvolvimento Urbano, Conselhos Municipais (de direitos, tutelares, de assistência e de saúde), Universidade do Vale do Acaraú, Poderes Legislativo e Judiciário, Pastoral da Criança, Apae, Diocese, igrejas, Sesc (Serviço Social do Comércio), Sesi (Serviço Social da Indústria), liga de futebol e liga das escolas de samba. A partir destas alianças e parcerias, foram propostas ações de prevenção ao uso de drogas; combate à prostituição infanto-juvenil; ampliação das atividades de socialização, cultura e lazer; educação ambiental; criação de uma equipe médica especificamente voltada para o atendimento da saúde do adolescente; realização de festivais nas escolas e inclusão das crianças portadoras de necessidades especiais, entre outros.

CADERNOS GESTÃO PÚBLICA E CIDADANIA, V. 13, N.52 - JAN./JUNHO 2008 
Por fim, o Comitê Sobral Criança Cidadã centra-se na questão da profissionalização e da proteção dos direitos das crianças e adolescentes. Participam deste comitê um número maior de secretarias municipais e de entidades ligadas ao setor privado, dentre elas: Secretarias Municipais de Saúde e Assistência Social, Educação, Cultura, Desenvolvimento Urbano, Indústria e Comércio, Universidade Vale do Acaraú, Conselhos Municipais (tutelar, de direitos e de assistência social), Ministério do Trabalho, Detran, Sociedade de Apoio à Família Sobralense, Sociedade Pró-Infância, Federação Sobralense das Associações Comunitárias, Diocese, igrejas, Associação dos Radialistas, Sesi (Serviço Social da Indústria), Sebrae (Serviço Brasileiro de Apoio às Micro e Pequenas Empresas), Senac (Serviço Nacional do Comércio) e Clube dos Diretores Lojistas. São discutidos desde projetos relacionados às ações preventivas de garantia das proteções e direitos às crianças e adolescentes, como projetos relacionados ao uso de drogas, ao tabagismo, ao uso de bebidas alcoólicas e à prostituição infantil, até projetos relacionados ao treinamento profissional dos jovens. Para tanto, foram construídos a Casa João e Maria (para a passagem e acolhida das crianças e adolescentes em situação de risco), o SOS Criança, o Abrigo Familiar, e a Escola de Artes e Ofícios (para a profissionalização dos jovens na conservação e restauração do patrimônio histórico).

A descrição destes comitês evidencia os pilares do Programa Sobral Criança: por um lado, a intersetorialidade nas políticas sociais, integrando atores governamentais entre si e com a sociedade, e garantindo uma maior eficiência como resultado da soma de esforços; por outro lado, a participação da sociedade e a democratização da gestão como forma de garantir à população voz ativa na determinação e implementação destas políticas.

O Projeto Trevo de Quatro Folhas ${ }^{3}$, por sua vez, é um programa mais recente, criado a partir de 2001, que deu continuidade às ações voltadas à saúde da gestante e do recémnascido iniciadas pelo Programa Sobral Criança. Este programa foi criado pela Secretaria de Saúde, como conseqüência da percepção de lacunas no atendimento a este público. A partir de um processo de investigação dos óbitos de crianças menores de um ano e de algumas gestantes, foram identificadas as principais falhas existentes no atendimento, desde o pré-natal até o parto. A falta de informações e de apoio, entre outros fatores, fazia com

\footnotetext{
${ }^{3}$ Para mais informações sobre o Projeto Trevo de Quatro Folhas, ver LOTTA, Gabriela Spanghero. Trevo de Quatro Folhas. In: TEIXEIRA, Marco; GODOY, Melissa; CLEMENTE, Roberta. 20 Experiências de Gestão Pública e Cidadania: Ciclo de Premiação 2005. São Paulo: Programa Gestão Pública e Cidadania, 2006.
} 
que muitas gestantes em situação de risco, por exemplo, não ficassem de repouso, como receitado pelo médico, colocando sua saúde e de seu filho em risco. Por outro lado, havia problemas no lado da oferta de saúde, como a demora para o início do programa de prénatal e falhas neste atendimento, entre outros.

Baseado nestas carências, foi criado o Projeto Trevo de Quatro Folhas, estruturado em quatro fases: 1) Gestão do Cuidado no Pré-Natal; 2) Gestão do Cuidado no Parto e Puerpério; 3) Gestão do Cuidado no Puerpério e Período Neonatal; e 4) Gestão do Cuidado nos Dois Primeiros Anos de Vida. Considerando-se que algumas destas ações já haviam sido iniciadas com o Programa Sobral Criança, o Projeto Trevo de Quatro Folhas deve ser visto menos como a criação de um novo programa e mais como a renovação de um programa já existente, superando suas carências e propondo novas linhas de ação.

O programa baseia-se no constante acompanhamento, monitoramento e avaliação de resultados. Há indicadores utilizados para medir a eficiência de cada uma das fases descritas acima, que são compartilhados com toda a equipe envolvida no projeto, visando a sua constante melhoria.

No caso de falecimento de gestantes e bebês, o Projeto Trevo de Quatro Folhas conta com o apoio de um comitê, que recebe todas as informações sobre estes óbitos. A partir destes dados, o Comitê de Prevenção da Mortalidade Materna, Perinatal e Infantil de Sobral reúne-se mensalmente para discutir cada um dos óbitos e prever as ações e melhorias necessárias. Este comitê é formado por representantes da Santa Casa, da Diretoria Regional de Saúde, do Conselho da Mulher, do Conselho Municipal de Saúde, do Conselho Municipal da Criança e Adolescente, do Hospital Dr. Estevan, da Escola Saúde da Família, do Projeto Trevo de Quatro Folhas, da Vigilância Sanitária, da Faculdade de Medicina e Enfermagem da Universidade Vale do Acaraú, do Conselho Regional de Medicina e outros, numa estrutura similar aos comitês do Programa Sobral Criança, agregando diversos atores governamentais e não-governamentais. São mais de 1000 pessoas trabalhando em conjunto nestes comitês para a redução da morbimortalidade materna e infantil.

O envolvimento da comunidade é bastante significativo, principalmente por meio do trabalho realizado pelos agentes comunitários de saúde, mães sociais e padrinhos e madrinhas sociais. Os agentes comunitários de saúde são pessoas escolhidas dentro da própria comunidade, que passam a ser vinculadas aos programas de saúde desenvolvidos

CADERNOS GESTÃO PÚBLICA E CIDADANIA, V. 13, N.52 - JAN./JUNHO 2008 
pelo Estado e a realizar visitas domiciliares na região onde moram, trabalhando na promoção da saúde. As mães sociais são mulheres da comunidade que recebem treinamento e capacitação para o cuidado com as novas mães e recém-nascidos e são remuneradas para isso. Já as madrinhas e padrinhos sociais são pessoas que adotam uma família e que contribuem com uma quantia mensal, revertida para a alimentação das gestantes e crianças com carências nutricionais, e com outros objetos e utensílios, como fogões, roupas e sapatos. Estes indivíduos podem ou não se identificar - escolhendo identificar-se, há a opção de acompanhar as mães e bebês que estão sendo ajudados.

\section{A importância da participação popular}

Os comitês do Programa Sobral Criança estão organizados de maneira relacionada aos eixos centrais da política social do município, quais sejam a saúde, a educação e a assistência social. O comitê do Projeto Trevo de Quatro Folhas funciona especificamente na área de saúde, com foco em reduzir os índices de morbimortalidade materna e infantil.

Estes comitês, portanto, funcionam como espaços para a discussão das políticas sociais do município, para a informação e publicização do que vem sendo feito. São órgãos mistos, relativamente institucionalizados, mas não formalizados, capazes de agregar os diversos segmentos da sociedade. Sua importância, principalmente como instância de discussão das políticas sociais, não pode ser subestimada. A população participa da determinação dos objetivos das políticas, da discussão do processo e da maneira de execução dos programas e da gestão destes projetos e programas, propondo alternativas de melhoria ao longo do trajeto.

As opiniões abaixo, da população de Sobral sobre o Programa Sobral Criança, evidenciam o papel da intersetorialidade e da co-gestão:

No Bairro de Terreno Novo, hoje, a gente articula com todas as forças existentes, da Igreja Católica aos protestantes, ao posto de saúde, à escola, às associações, à creche... para tudo, a gente se reúne para discutir os problemas do nosso bairro. (Dolores Gama - diretora da Escola Mocinha Rodrigues, Programa Gestão Pública e Cidadania, 2007)

Na criação de uma creche, os professores e diretores foram escolhidos pela comunidade entre as pessoas da comunidade - eu percebo isso como uma forma de articulação e participação popular grande. (Chiquinho Silva - presidente

CADERNOS GESTÃO PÚBLICA E CIDADANIA, V. 13, N.52 - JAN./JUNHO 2008 
Associação Comunitária Benedita Tonho, Programa Gestão Pública e Cidadania, 2007).

Estas frases evidenciam o fato de que a própria população percebe o governo como sendo altamente permeável e aberto à participação popular, além de tratar da importância da articulação entre os diversos segmentos para a determinação das políticas sociais.

Percebe-se, por outro lado, que a gestão governamental vê a população e as entidades que atuam na área da criança e do adolescente como fundamentais na definição e implementação das políticas sociais do município de Sobral.

Considerando-se, porém, a grande heterogeneidade dos atores que atuam na defesa dos direitos das crianças e dos adolescentes e a precariedade das condições em que funcionam, o Estado tem o importante papel de tentar reverter estas deficiências para garantir que a participação popular se dê no melhor contexto possível. Se as pessoas não têm iguais condições de participar das discussões, seja por incapacidade técnica, seja porque o ambiente físico não permite, é dever do Estado garantir que estes obstáculos sejam ultrapassados, investindo na capacitação dos recursos humanos e na melhoria da infraestrutura.

É por esta razão que o município de Sobral tem investido fortemente nestes dois pilares: na capacitação dos recursos humanos, tanto governamentais quanto não-governamentais, e na construção e melhoria de equipamentos públicos e infra-estrutura urbana.

\section{Impactos do Programa}

Considerando-se o descompromisso dos gestores municipais para com as políticas sociais do município de Sobral até meados da década de 90, os atuais indicadores econômicos e sociais são altamente positivos, porque mostram a reversão de uma situação de baixos índices de desenvolvimento humano para um cenário de melhoria das condições de vida da população, principalmente de baixa renda. A tabela 1 apresenta algumas destas evoluções, comparando a situação do município num período de dez anos: de 1991 a 2000.

Neste período de dez anos, a cidade de Sobral cresceu a uma taxa média anual de 2,32\%, passando de 127.315 habitantes em 1991 para 155.276 em 2000. Este crescimento foi maior do que o verificado no Estado do Ceará, que cresceu, neste mesmo período, a uma taxa média anual de 1,80\% (PNUD, 2002).

CADERNOS GESTÃO PÚBLICA E CIDADANIA, V. 13, N.52 - JAN./JUNHO 2008 
Considerando-se que aproximadamente $87 \%$ da população de Sobral vive na zona urbana (PNUD, 2002), este crescimento acelerado da população poderia ter causado grandes prejuízos à infra-estrutura da cidade, sobrecarregando um sistema já precário de atendimento à população. Mas não foi o que aconteceu.

Por conta da decisão do poder público de investir prioritariamente nas políticas sociais, chamando a população e as entidades sociais para uma gestão conjunta dos objetivos e definições destas políticas, foi possível alterar o cenário existente até então. Vimos este compromisso em dois programas adotados pelo governo municipal, o Programa Sobral Criança e o Projeto Trevo de Quatro Folhas, apresentados anteriormente.

De 1991 a 2000, a mortalidade infantil foi reduzida em 42\% - a queda é de 66\% se considerarmos os indicadores de 2005 em comparação a 1991. A esperança de vida cresceu quase 8 anos, a taxa de fecundidade caiu para 3,2 filhos por mulher, houve redução na taxa de analfabetismo de $28 \%$, aumento no número de anos de estudo em 1,2 anos e crescimento da renda per capita média de 46,35\% (PNUD, 2002).

Tabela 1: Evolução de alguns indicadores na cidade de Sobral (1991 a 2000)

\begin{tabular}{|l|c|c|}
\hline \multicolumn{1}{|c|}{ Indicadores } & $\mathbf{1 9 9 1}$ & $\mathbf{2 0 0 0}$ \\
\hline População & 127.315 & 155.276 \\
\hline Mortalidade até 1 ano de idade (por nascidos vivos) & $66,8 / 1000$ & $39 / 1000$ \\
\hline Esperança de vida & 60,6 anos & 68,3 anos \\
\hline Taxa de analfabetismo & 43,7 & 31,6 \\
\hline Renda per capita média (R\$ 2000) & 103,6 & 151,6 \\
\hline Água encanada & 60,9 & 84,2 \\
\hline Energia elétrica & 79,9 & 95,3 \\
\hline Índice de Desenvolvimento Humano Municipal & 0,581 & 0,699 \\
\hline
\end{tabular}

Fonte: PNUD, 2002.

A maioria dos indicadores, além de ter apresentado melhora relativa em relação à situação de 1991, melhorou também em relação à média apresentada pelos demais municípios do Estado do Ceará.

De acordo com o PNUD (2002), o índice de desenvolvimento humano municipal de Sobral é de 0,699, colocando-a como uma região de médio desenvolvimento humano (IDH entre 
0,5 e 0,8). Em relação aos outros municípios do Brasil, está em uma situação intermediária: ocupa a posição 3003 entre os 5507 municípios. Em relação aos outros municípios do Estado do Ceará ${ }^{4}$, no entanto, vemos que sua situação é excelente: Sobral ocupa a sétima posição do Estado, ou seja, apenas seis municípios estão em situação melhor, enquanto 177 municípios estão em situação pior ou igual.

Foram muitos os prêmios recebidos pela cidade de Sobral nos últimos anos. Foi premiado, em 1999 e 2005, pelo Programa Gestão Pública e Cidadania, da Escola de Administração de Empresas de São Paulo da Fundação Getulio Vargas (EAESP/FGV), considerado Município Saudável pela Organização Pan Americana de Saúde e Município Aprovado pelo UNICEF. Mais recentemente, recebeu o Prêmio Sérgio Arouca de Gestão Participativa do Ministério da Saúde, o Certificado de Município Verde 2005 (pelos programas, projetos e ações de conservação de uso sustentado dos recursos naturais), Prêmio Objetivos do Milênio - ODM Brasil 2005 (pela redução da taxa de mortalidade infantil e melhoria da saúde da gestante), o Prêmio Inovação em Gestão Educacional 2006, entre muitos outros (Prefeitura de Sobral, 2007). Estes prêmios apenas evidenciam o reconhecimento pelos esforços empreendidos nos últimos dez anos, que colocam Sobral como um modelo de participação popular a ser seguido por outras cidades no Brasil e no mundo.

\footnotetext{
${ }^{4}$ O Ceará é um dos estados mais pobres do país, ocupando a vigésima posição entre os 27 estados brasileiros,
} de acordo com o PNUD (2002). 


\section{Referências Bibliográficas}

CARNEIRO, Carla Bronzo Ladeira. Programa Sobral Criança. In: FARAH, Marta Ferreira Santos e BARBOZA, Hélio Batista. Novas Experiências de Gestão Pública e Cidadania: Ciclo de Premiação 1999. São Paulo: Programa Gestão Pública e Cidadania, 2000.

IBGE - Instituto Brasileiro de Geografia e Estatística. Resultados da Amostra do Censo Demográfico 2000 - Malha municipal digital do Brasil: situação em 2001. Rio de Janeiro: IBGE, 2004. Disponível em http://www.ibge.gov.br.

IBGE - Instituto Brasileiro de Geografia e Estatística. Resultados da Amostra do Censo Demográfico 1991. Disponível em http://www.ibge.gov.br.

IBGE - Instituto Brasileiro de Geografia e Estatística. Resultados da Amostra do Censo Demográfico 2000. Disponível em http://www.ibge.gov.br.

IPECE - Instituto de Pesquisa e Estratégia Econômica do Ceará. HOLANDA, Marcos et al. A Política Social do Ceará no Período 2002/2005. Texto para discussão n. 29. Fortaleza, dezembro de 2006.

IPECE - Instituto de Pesquisa e Estratégia Econômica do Ceará. Perfil Básico Municipal: Sobral. Fortaleza, 2005.

LOTTA, Gabriela Spanghero. Trevo de Quatro Folhas. In: TEIXEIRA, Marco; GODOY, Melissa; CLEMENTE, Roberta. 20 Experiências de Gestão Pública e Cidadania: Ciclo de Premiação 2005. São Paulo: Programa Gestão Pública e Cidadania, 2006.

PNUD - Programa das Nações Unidas para o Desenvolvimento. Atlas do Desenvolvimento Humano no Brasil. Publicado em parceria com o IPEA e Fundação João Pinheiro (MG). 2002. Disponível em www.pnud.org.br/atlas.

Prefeitura de Sobral. http://www.sobral.ce.gov.br. Acesso em agosto/2007.

PROGRAMA GESTÃO PÚBLICA E CIDADANIA. Práticas Públicas em Construção. Vol 1. Material em DVD. Fevereiro de 2007.

SPINK, Peter. Parcerias e Alianças com Organizações Não-Estatais. In: CACCIA-BRAVA, Silvio; PAULICS, Veronika; SPINK, Peter (org.). Novos contornos da gestão local: conceitos em construção. São Paulo: Polis e Programa Gestão Pública e Cidadania, 2002.

Artigo recebido em 10/08/2007 e aceito em 11/12/2007. 